\title{
US Immigration paths for scientific researchers: Part 2
}

\section{By Marco Pignone}

This article is the second part of a series in MRS Bulletin on achieving a path to a green card in the United States. It will cover and compare the criteria for EB-1A classification for foreign nationals of extraordinary ability, EB-1B classification for foreign nationals who are outstanding researchers and professors, and information on the National Interest Waiver category.

$\mathrm{P}$ art 1 of this series (see MRS Bulletin, May 2020, p. 396) provided an overview of the US immigration process for scientific researchers. If you are not familiar with the F-1 student visa, OPT (Optional Practical Training), which provides three years of work authorization after graduation, or the Program Electronic Review Management (PERM) labor certification process, and why you should avoid it, we invite you to read that article at www.mrs. org/bulletin/career-feature-1. This article will discuss the $\mathrm{H}-1 \mathrm{~B}$ visa and the $\mathrm{J}-1$ visa and the impact each one has on your own personal immigration path.

\section{The $\mathrm{H}-1 \mathrm{~B}$ visa}

If you are an F-1 student who has previously graduated and are nearing the end of your three years of OPT work authorization, you should start planning to get an $\mathrm{H}-1 \mathrm{~B}$ visa, which can give you up to six years of legal status or more, or a J-1 visa (up to five years). The first question you have to ask yourself is whether you want to go into industry or complete a postdoc program. If you want to go into industry or remain in industry if you are working for a private company during your OPT, then you should enter an $\mathrm{H}-1 \mathrm{~B}$ visa lottery each year, giving yourself a total of three chances. There are a limited number of $\mathrm{H}-1 \mathrm{~B}$ visas for private companies, while there are an unlimited number of $\mathrm{H}-1 \mathrm{~B}$ visas for university postdoc positions.

For this reason, the United States runs a lottery every year around April 1 for private employers. Your potential employer

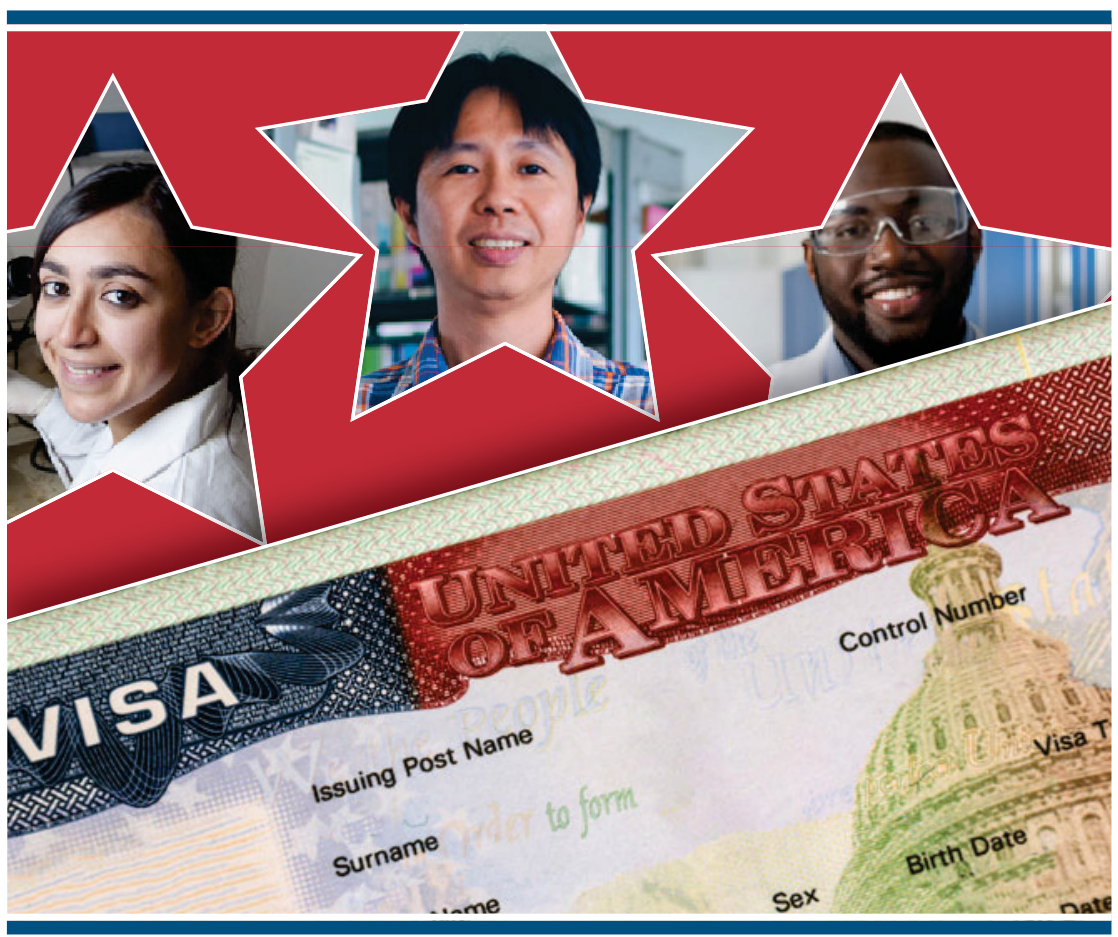

has to file an $\mathrm{H}-1 \mathrm{~B}$ petition for you and hope that you win the lottery. Under new rules introduced in 2020, the employer only has to "register" to enter the lottery, and then they file the actual petition only if you win the lottery. Depending on how many petitions are received by the Immigration Service each year, the odds of winning the lottery could be anywhere from 1 in 2 to 1 in 4 .

If you were an F-1 student, you should try to enter the H-1B lottery each year of your three years of OPT. If you graduated from a foreign $\mathrm{PhD}$ program, you may also use the H-1B visa lottery if you want to work for a private employer within the United States. If you win the lottery, you have up to six years of $\mathrm{H}-1 \mathrm{~B}$ status, as long as you continue your employment with your H-1B employer or in a "same or similar" position with another private employer. There are also laws allowing you to extend your H-1B status beyond six years if you have an approved I-140 petition (this is the EB-1 or National Interest Waiver [NIW] petition mentioned in Part 1 of the series, which will be discussed in more detail in a future article.

\section{The J-1 visa}

It can be difficult to find an employer willing to file an $\mathrm{H}-1 \mathrm{~B}$ petition for you, and as the odds of winning the H-1B lottery are usually less than $50 \%$, you must have a backup plan. For most scientists, their backup plan will be a postdoc position that offers a J-1 visa. A J-1 visa gives you up to five years of legal status to work for your J-1 employer. Many universities offer the $\mathrm{J}-1$ in one-year intervals and extend their postdocs' status each year, assuming they have sufficient funding for their research. If you enter the United States on 
a J-1 visa or change to J-1 status from F-1 student status, your university will give you a Form DS-2019 with an expiration date. That date is when your status expires in the United States, and you should ask your employer to extend it as early as possible. Some universities will extend your status well in advance of the expiration, while others will wait until the last minute, especially if you are not proactive in raising the issue.

The most important thing to remember about the $\mathrm{J}-1$ visa is that some $\mathrm{J}-1$ visas are subject to the "two-year rule," also known as the "two-year foreign residence requirement." If the J-1 visa in your passport indicates "subject to section 212(e)," then you are required to return to your home country (note: not just leave the United States, but actually return to your home country) and spend two years there before applying for a green card in the United States or changing your status in the United States.

There are rules that determine whether or not you will be subject to the two-year rule, but you should be aware of them before you accept a J-1 visa. Most J-1s subject to the rule can avoid this requirement through what is called a "waiver." While there are three ways to apply for this waiver, $99 \%$ of them are "no objection" waivers. To obtain a no-objection waiver, your country must agree to a waiver of the two-year rule. The idea behind the J-1 twoyear rule is that you are learning skills in the United States that you can later use to help your home country. However, if your country agrees, the United States will grant you a waiver of the rule.

If you are from a country that generally grants the no-objection, the two-year rule can cause problems with the timing of your green card application (which is made by filing a Form I-485), but you can still obtain a J-1 visa, and there is always a way to work around this issue. The problems are caused by a law that states that if you have applied for a green card, you can no longer extend your J-1 visa. This can be a problem, as you must have valid J-1 status or a work authorization card (also known as an Employment Authorization Document [EAD]) to work legally in the United States. When you submit a green card application, you always simultaneously submit an application for an EAD, as well as a travel document. However, the US Citizenship and Immigration Services often takes from three to six months to issue an EAD and travel document (also known as "advance parole").

Another law states that you automatically abandon your green card application if you travel outside of the United States before you receive the $\mathrm{EAD} /$ travel permit. It is extremely important that you (1) have more than six months left on your $\mathrm{J}-1$ at the time you submit your green card application, and (2) have no travel plans for six months. Historically, it has taken three to four months for the Immigration Service to issue an $\mathrm{EAD} /$ travel document, but there was a brief time in 2019 when it was taking up to eight months, so we prefer to file for clients with seven or more months left on their J visas.

I will explain the important issue of timing in more detail in future articles, and we will look at some examples of common timelines in this situation from some of our actual cases. There are many factors that determine when you should file a green card application, including your career plans, when your current status expires, whether you have a new job and employer prepared to file an $\mathrm{H}-1 \mathrm{~B}$ petition for you, what your qualifications are such as number of citations, whether you are married, and your spouse's immigration status, etc. With individualized consultations, we draw a timeline for our clients, which makes the situation more clear in relation to these various factors.

\section{The $\mathrm{H}-1 \mathrm{~B}$ visa and green cards by labor certification}

In general, very few private companies will file a petition for you to get a green card unless you win the H-1B lottery and have worked for the company for at least one or two years. An H-1B visa can be valid for up to six years; however, if a company has filed a labor certification for you more than one year before the expiration of your H-1B status, you may extend your H-1B status beyond six years. This is necessary, as it can take years from the filing of the labor certification until you are allowed to file a green card application because of visa backlogs.

It should also be noted that if you have a tenure track teaching position, it is possible for a university to file a petition for a green card for you in the EB-1B category, to be discussed in further detail in a future article.

\section{Self-petitioning for a green card through the EB-1A and NIW categories}

Because it can be difficult to obtain an $\mathrm{H}-1 \mathrm{~B}$ visa to work for a private company, it is important that you understand how you can self-petition for a green card without any help from an employer. The EB-1A category, or "extraordinary ability," has extremely high standards, but fortunately, only people from China and India use this category due to visa backlogs. If you are from any other country, you will almost certainly file your self-petition in the NIW category, which requires high qualifications, but far lower than those required in the EB-1A category.

Continue to follow this series of articles in MRS Bulletin. The next article will discuss how to self-petition in the EB-1A and NIW categories.

Marco Pignone, immigration lawyer at the Philadelphia law firm Getson \& Schatz, P.C. (https://researchergreencard.com/), currently focuses on EB-1A and NIW petitions for immigrant researchers. Since 2001, he has represented immigrants in a wide range of immigration matters.

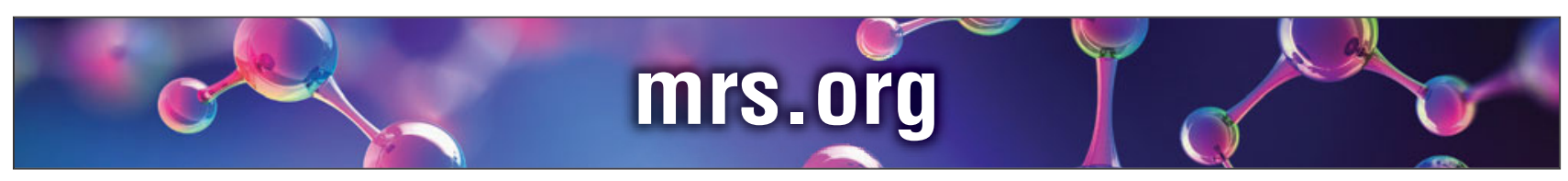

